\title{
DIMENSÃO RITUAL DO COMPORTAMENTO DE CONSUMO
}

\section{RESUMO}

No dia-a-dia, as pessoas participam regularmente de diversas atividades ritualizadas, seja no lar, no trabalho ou no lazer, tanto como indivíduos quanto como membros de uma comunidade maior. A pessoa média também depende de diversos eventos rituais para marcar os acontecimentos significativos de sua vida, como a formatura, o casamento e a morte. Apesar dessas experiências rituais abrangentes e plenas de significado, a pesquisa sobre o consumidor tem falhado em reconhecer esse amplo domínio comportamental. Este artigo apresenta e elabora o construto ritual como veículo para a interpretação do comportamento de consumo e apresenta os resultados de dois estudos exploratórios que investigam o conteúdo artefatual e psicossocial dos rituais de cuidados pessoais de adultos jovens.

\section{Dennis W. Rook}

Marshall School of Business - University of Southern California

ABSTRACT In daily living, people participate regularly in a variety of ritualized activities at home, work, and play, both as individuals and as members of some larger community. The average person also relies on various ritual events to mark such significant life passages as graduation, marriage, and death. Despite these pervasive and meaningful ritual experiences, consumer research has largely failed to recognize this extensive behavioral domain. The present article introduces and elaborates the ritual construct as a vehicle for interpreting consumer behavior and presents the results of two exploratory studies that investigate the artifactual and psychosocial contents of young adults' personal grooming rituals.

PALAVRAS-CHAVE Comportamento do consumidor, ritual, pesquisa qualitativa, etnografia, artefatos.

KEYWORDS Consumer behavior, ritual, qualitative research, ethnography, artifact. 
São 3:29 da madrugada. Harvey Reeves adormeceu há mais de duas horas, durante a entrevista com o segundo convidado de David Letterman, e a TV ainda está ligada. O canal se despede tocando o hino nacional americano. Embora parte substancial do público desse ritual que precede o amanhecer esteja na horizontal, a cerimônia é, ainda assim, conduzida com a dignidade patriótica adequada. Dali a algumas horas, Harvey acorda ao som de um alarme eletrônico e, como milhões de outras pessoas, realiza um ritual que o transporta dos braços de Morfeu ao escritório. Primeiro, Harvey se arrasta até a cozinha para ligar a cafeteira. Depois liga o rádio. Em cerca de dez minutos termina de folhear o jornal e se encaminha para o chuveiro. Harvey tem gastado um pouco mais de tempo cuidando de si ultimamente e acabou de acrescentar a aplicação de um hidrante à sua rotina matinal. Às 7:03 ele liga a secretária eletrônica, deixa o apartamento e, a bordo de seu 280-Z, sai às ruas. A caminho do trabalho, assiste à missa matinal na Igreja de St. Vincent e posta um cartão de aniversário endereçado à sua tia Helen.

No escritório, o período da manhã é especialmente difícil por causa de intermináveis negociações com uma equipe de executivos japoneses. O estilo japonês de barganhar, muito formal e lento, está levando Harvey à loucura. O almoço é um tédio: uma comemoração da aposentadoria do chefe do departamento de contabilidade. A atenção de Harvey vagueia: "O que dar de presente de Natal para minha mãe? Vamos ficar aqui mesmo ou viajar para algum lugar?". Depois de uma tarde de entrevistas formais com candidatos a uma vaga, Harvey começa a pensar no encontro às cegas que terá à noite. Encontra Susan no Red Onion para um jantar de apresentação mútua e depois vai com ela ao estádio para beber cerveja, torcer por duas horas e ver os Clippers serem derrotados novamente. Susan concluiu que Harvey é um chato, de modo que, depois do jogo de basquete, vem o incômodo ritual de desengajamento social. Enquanto se prepara para dormir, Harvey faz seus 50 abdominais, puxa um pouco de ferro e consome uma tigela de cereal ao mesmo tempo em que assiste ao programa de Joan Rivers. Do outro lado da cidade, Susan prende o cabelo, programa o despertador, aplica uma máscara facial, ora e adormece lendo um romance de Agatha Christie.

Esse cenário imaginário foi apresentado para ilustrar o quanto o ritual social permeia a vida rotineira moderna. Cada uma dessas atividades hipotéticas está associada a um tipo distinto de ritual: midiático, patriótico, doméstico, religioso, de cuidado pessoal, de dar presentes, de negócios, de alimentação, de rito de passagem, de feriado, romântico, atlético e de sono. Mas apesar do forte envolvimento das pessoas com o ritual, a pesquisa social tem falhado em concentrar-se sobre fenômenos rituais pós-industriais. Mesmo os antropólogos tendem mais a estudar os rituais de consumo de uma remota tribo amazônica do que os rituais de mercado de um shopping center de um subúrbio americano. Com isso, uma dimensão proeminente da experiência de consumo permanece território virtualmente desconhecido. Essa negligência surpreende porque o comportamento ritual muitas vezes envolve trocas extensas de bens e serviços que freqüentemente se consumam em ocasiões dramáticas, cerimoniais e até mesmo solenes. Dar presentes, por exemplo, é um aspecto central de muitos rituais de troca (Sherry, 1983). Além disso, o preparo e o consumo de comida são freqüentemente associados a eventos rituais específicos (Farb e Armelagos, 1980). O consumo em geral já foi até interpretado como o ritual essencial da vida moderna (Wright e Snow, 1980). A relativa falta de interesse nos fenômenos rituais das culturais pós-industriais pode ser devida ao conceito persistente, ainda que errôneo, de que os rituais são expressões exclusivamente religiosas e um comportamento regressivo primitivo (Moore e Myeroff, 1977). As interpretações do comportamento ritual como sendo anacrônico (Ayer, 1985) e estando em deterioração (Douglas, 1974) não são convincentes porque a pessoa média participa todos os dias de numerosos sistemas de comportamento ritualizado (Browne, 1980).

\section{UM MODELO DE EXPERIÊNCIA RITUAL}

Fenômenos rituais são tipos altamente variados de comportamento expressivo que ocorrem nos mais diversos ambientes. Edmund Leach (1968) observa que há forte discordância, mesmo entre os que se especializaram no estudo do ritual, sobre o uso do termo "ritual". Pesquisas publicadas sobre a experiência ritual humana vêem principal e tradicionalmente da antropologia cultural, da história das religiões, da sociologia de campo e da psicologia dinâmica. Recentemente, emergiu um pequeno número de estudos sobre comportamento ritual voltados para os negócios no campo da pesquisa de comportamento das organizações (Feldman, 1977) e no da pesquisa em marketing (Kehret-Ward, Johnson e Louie, 1985; Rook e Levy, 1983; Solomon e Anand, 1985). Cada área se baseia em seu próprio conjunto de construtos prediletos, o que dificulta a interpretação comparativa. Como as experiências rituais individuais são tão amplas, variadas, complexas e significativas, é razoável perguntar se seria possível ou útil derivar uma definição única de ritual que abranges- 
se toda essa considerável diversidade. Haverá elementos estruturais e de conteúdo comuns a todos os modos de comportamento ritual? A discussão que se segue vai responder afirmativamente às duas perguntas.

\section{Definição de ritual}

Muitas definições existentes de ritual são insatisfatórias porque restringem a experiência ritual a contextos religiosos ou místicos. Algumas interpretações consideram erroneamente o ritual como sendo um comportamento essencialmente primitivo e regressivo, enquanto outras retratam os rituais como coisas que ocorrem somente em larga escala em ambientes públicos. A definição a seguir interpreta o comportamento ritual como aspecto positivo e significativo da experiência humana tanto rotineira quanto extraordinariamente:

O termo ritual refere-se a um tipo de atividade expressiva e simbólica construída de múltiplos comportamentos que se dão numa seqüência fixa e episódica e tendem a se repetir com o passar do tempo. O comportamento ritual roteirizado é representado dramaticamente e realizado com formalidade, seriedade e intensidade interna.

Essa definição incorpora tanto os elementos estruturais que caracterizam o comportamento ritual quanto os componentes qualitativos que distinguem o ritual de modos de comportamento assemelhados.

A experiência ritual se constrói em torno de uma seqüência episódica de eventos. Por exemplo, um ritual religioso poderia começar com uma procissão, seguida de uma invocação, de hinos, um sermão, uma oferta e um recolhimento. Uma determinada seqüência de comportamentos rituais pode ser relativamente breve e simples (rituais de saudação e despedida) ou mais elaborada (cerimônias cívicas), mas a compreensão de qualquer ritual específico exige uma apreciação dos diversos eventos comportamentais que o compõem. Outra característica distintiva dos rituais é a ligação das seqüências de eventos episódicos de maneira exata e fixa. Um elemento de ação é quase sempre seguido ou precedido de uma série de eventos que não varia. A ação ritual é concebida para adequar-se a roteiros estereotipados, e agindo de acordo com o roteiro prescrito, é considerada alguma coisa intrinsecamente recompensadora (Bird, 1980), embora alguns rituais sejam mais casuais do que outros sob esse aspecto. Embora seja considerado profano alterar a seqüência de eventos de um ritual religioso, a ordem dos eventos na festa de aniversário de uma criança parece ser especificada com menor rigidez. Mas, mesmo aqui, há idéias comuns sobre o momento apropriado para abrir os presentes, participar de jogos e distribuir bolo e sorvete.

Uma terceira característica do comportamento ritual é a repetição da seqüência de eventos ao longo do tempo. Um ritual tende a se realizar da mesma maneira a cada vez que é observado, de maneira que os eventos rituais funcionam como dispositivos mnemônicos que trazem à tona pensamentos e sentimentos específicos no indivíduo (Mead, 1956). Assim, geram-se os sentimentos adequados a cada vez que se dramatiza um ritual. Podem surgir variações no conteúdo ou na seqüência, mas isso tende a ocorrer lentamente e muitas vezes enfrenta considerável resistência. Sob esse aspecto, os rituais são semelhantes aos hábitos e costumes comportamentais.

Os rituais têm outras características em comum com os hábitos comportamentais; de fato, alguns rituais são realizados mais ou menos habitualmente (serviços religiosos, cuidados pessoais). Os rituais e hábitos comportamentais representam conjuntos sobrepostos: nem todos os hábitos envolvem rituais, e nem todos os rituais representam necessariamente uma atividade habitual. Por exemplo, um casamento é um ritual social comum, mas não um hábito. E comer uma rosquinha de chocolate pode ser um hábito matinal, mas não constitui consumo ritualizado. Normalmente, um ritual é uma experiência maior e plural, enquanto os hábitos tendem a ser comportamentos singulares, como amarrar os sapatos, enrolar o cabelo no dedo indicador ou tomar vitaminas pela manhã. Embora alguns hábitos sejam complexos e altamente envolventes (como os vícios), muitas vezes são menos significativos pessoalmente do que os rituais, e seria depreciar um ritual descrevê-lo como meramente habitual (Erikson, 1977).

Os rituais se diferenciam dos hábitos, também, por sua roteirização dramática. Os roteiros dos rituais normalmente têm começo, meio e fim (Leach, 1958), representados por participantes que assumem identidades dramáticas específicas (Bird, 1980). A experiência ritual pode ser realizada cerimonialmente, com formalidade elaborada e numerosos elementos teatrais. Vêm à mente imagens de velas e cornetas, invocações e comemorações, fantasias e concursos, paradas, pompa e circunstância. No nível mais mundano, os rituais também têm uma dimensão dramática. As apresentações sociais, por exemplo, podem envolver intrincados rituais de etiqueta, e rituais comuns, como jantares de aposentadoria, podem tornar-se melodramáticos, tendendo a estimular emoções intensas entre os participantes (Bird, 1980, Bossard e Boll, 1950). Os grandes ritos de passagem, como formaturas e casamentos, marcam importantes transições de status social e estimulam grande envolvimento psicológico e forte ansiedade. Até 
a festa de aniversário de uma criança envolve preocupações sérias para os participantes envolvidos: Quem veio? Quem não veio? Os presentes são numerosos ou insuficientes? Observou-se reciprocidade? E os rituais servem para incluir ou excluir pessoas da família ou da comunidade. Isso se vê de forma mais acentuada em ambientes religiosos, fraternos e cívicos, onde os rituais muitas vezes são bastante solenes.

Finalmente, os rituais desencadeiam uma resposta comportamental imediata (Leach, 1976). O ritual é uma linguagem corporal que opera como um símbolo natural, facilitando as interações entre pessoas. Nos Estados Unidos, até um aperto de mão é significativo, especialmente quando é recusado.

\section{Elementos do ritual}

A experiência ritual depende de quatro componentes tangíveis:

1. Artefatos rituais.

2. Roteiro do ritual.

3. Representação do(s) papel(éis) do ritual.

4. Platéia do ritual.

Como os rituais são representações dramáticas, essa análise assemelha-se ao uso que Goffman (1959) faz da metáfora dramatúrgica para o estudo da relação social humana. Os artefatos rituais muitas vezes assumem a forma de produtos de consumo (Douglas e Isherwood, 1979) que acompanham um ambiente ritual ou são nele consumidos: alimentos e bebidas, jóias, diplomas, velas ou vestes cerimoniais. Quando usados num contexto ritualístico, tais artefatos freqüentemente comunicam mensagens simbólicas específicas que integram o significado da experiência como um todo. Servem, também e mais genericamente, como símbolos rituais na forma mitológica de caracteres, ícones, logomarcas ou cores significativas. Os artefatos também são muitas vezes trocados entre os participantes do ritual (Belk, 1979; Sherry, 1983) ou usados para comunicação interpessoal, como no caso de cartões e telefonemas de boas-festas.

Um roteiro do ritual orienta o uso dos diversos materiais artefatuais. Como um roteiro cognitivo (Abelson, 1981), um roteiro de ritual prescreve um paradigma de consumo que pode incluir uso extensivo ou relativamente limitado de produtos. O roteiro identifica não só os artefatos a serem usados, mas também sua seqüência comportamental e quem deve usá-los. Alguns roteiros podem ser relativamente casuais (como os rituais de refeições em família) e permitir variação espontânea. Outros roteiros de rituais, como os de rituais cívicos e ritos de passagem, costumam ser mais formalmente roteirizados e constantes. Em casos extremos, como cerimônias religiosas e de iniciação, o roteiro do ritual é altamente codificado. Aqui, o roteiro do ritual pode constar de um documento por escrito, muito embora os roteiros não escritos, como os usados em muitos rituais de etiqueta, não sejam necessariamente menos formais.

Um roteiro de ritual é realizado por pessoas que ocupam diversos papéis rituais. Por vezes, o papel ritual de uma pessoa é explicitamente roteirizado, como em cerimônias de casamento e formatura. Em outros casos, o papel ritual pode ser roteirizado de forma vaga, como nas avaliações formais de pessoal. Incerteza, ansiedade ou embaraço podem surgir quando alguém é convocado para participar de um ritual com o qual não esteja familiarizado. Em muitos contextos as pessoas têm elevado grau de liberdade de representação de seu papel ritual. Freqüentemente podem optar impunemente por não participar de um ritual qualquer, ou optar por uma participação extensiva. Por exemplo, quase todos somos capazes de apontar uma vizinhança que se empolgue no Natal, com enormes decorações luminosas e diferentes representações seculares (Papai Noel e suas renas) e religiosas (presépio). A representação de um papel por alguém pode ser extensa, limitada, ou inexistente. Também pode ser passiva ou ativa. Hoje a mídia de massas permite participar de uma variedade de rituais religiosos, cívicos e culturais indiretamente e não como participante direto.

Finalmente, um ritual pode ser voltado para uma platéia maior do que a das pessoas com papel específico na realização do ritual. É fácil identificar a platéia alvo de muitos rituais. Por exemplo, quando um líder cívico toma posse, a platéia é a população em geral. Em determinados rituais domésticos, a platéia não costuma ir além da família imediata, enquanto em outros o público alvo pode ser mais incerto. Quem, por exemplo, é o alvo dos rituais do Dia de Colombo e do Dia da Marmota?

\section{TIPOLOGIA DO COMPORTAMENTO RITUAL}

Apesar da enorme variedade de experiências rituais, ainda é possível classificar os rituais em termos de suas origens comportamentais e observar elementos em comum entre rituais de tipos muito diferentes. Levy (1978, p. 20) aponta uma estrutura multidisciplinar para a construção de uma tipologia do comportamento ritual identificando cinco fontes primárias de comportamentos e significados: 
1. Biologia humana.

2. Metas e emoções individuais.

3. Aprendizado em grupo.

4. Valores culturais.

5. Crenças cosmológicas.

Qualquer comportamento específico pode ser produto de muitas fontes e também tende a ser estimulado por fatores ambientais e conjunturais. Ainda assim, tipos rituais distintos parecem se agrupar em torno de uma fonte específica. O Quadro 1 resume os elos entre uma fonte primária de comportamento e os tipos de experiência ritual que dela decorrem.

A compreensão da experiência humana do ritual é ampliada por uma apreciação da atividade ritual entre outras espécies de animais. Estudos etológicos freqüentemente descrevem sistemas rituais no reino animal, apontando formas paralelas de comportamento entre os humanos. Os rituais de animais são, literalmente, uma linguagem corporal cujo vocabulário é essencial para a função e a sobrevivência de uma espécie. Julian Huxley interpreta a ritualização do comportamento animal como promotora de comunicação livre de ambigüidade, estimuladora de padrões comportamentais específicos em outros, redutora da agressão e facilitadora da formação de elos sociais ou sexuais. (Huxley, 1966, p. 250). A ritualização humana é funcionalmente bastante parecida, mas nos sistemas rituais humanos o comportamento é herdado tanto cultural quanto geneticamente. Grande parte do ritual humano é criada conscientemente a partir da evolução da dinâmica de uma cultura qualquer. Conseqüentemente, a ritualiza- ção humana é mais variada e mutável do que a encontrada num grupo de espécie animal.

Uma das mais ricas fontes de experiência ritual humana está no sistema de crenças cosmológicas de uma cultura. Grande parte das primeiras discussões sobre o comportamento ritual humano enfatizava sua relação com a religião formal. Tylor (1871) descreveu o ritual como "a linguagem gestual da teologia" e Smith (1889) sugeriu que a representação ritual é simbolicamente mais importante do que a crença propriamente dita de uma determinada teologia. Numa discussão mais recente, Clifford Geertz explica como as práticas rituais solidificam doutrinas religiosas (1968, p. 669):

É no ritual [...] que, de alguma maneira, se gera a convicção de que as concepções religiosas são verídicas e as diretrizes religiosas são sólidas. É em alguma forma de cerimonial $[. .$.$] que os humores e motivações que os sím-$ bolos sagrados induzem nos homens [...] encontram-se e reforçam-se mutuamente.

O trabalho do historiador das religiões Mircea Eliade (1965, 1975) é típico da abordagem que enfatiza a dimensão cosmológica do ritual; ele vê os rituais principalmente como reencenações de protótipos sagrados (1965, p. 132). A associação entre ritual e propósito religioso tem sido tão forte que a análise das duas coisas quase sempre avançou lado a lado (Moore e Myerhoff, 1977, p. 1). Enquanto os rituais religiosos estão extensivamente documentados, os intérpretes por vezes restringem a expressão ritual de maneira excessivamente exígua, como estando limitada a ambientes religiosos.

\section{Quadro 1 - Uma tipologia da experiência ritual}

\begin{tabular}{|l|l|l}
\hline FONTE PRIMÁRIA DE COMPORTAMENTO & \multicolumn{1}{|c|}{ TIPO DE RITUAL } & \multicolumn{1}{c}{ EXEMPLOS } \\
\hline Cosmologia & $\begin{array}{l}\text { Religioso } \\
\text { Mágico } \\
\text { Estético }\end{array}$ & $\begin{array}{l}\text { Batismo, meditação, missa } \\
\text { “Cura”, jogo de azar } \\
\text { Artes cênicas }\end{array}$ \\
\hline Valores culturais & $\begin{array}{l}\text { Ritos de passagem } \\
\text { Cultural }\end{array}$ & $\begin{array}{l}\text { Formatura, casamento } \\
\text { Festivais, Dia dos Namorados, Dia da Marmota, Super Bowl }\end{array}$ \\
\hline Aprendizado grupal & $\begin{array}{l}\text { Cívico } \\
\text { Grupal pequeno }\end{array}$ & $\begin{array}{l}\text { Parada do Memorial Day, eleições, julgamentos } \\
\text { Dia da Panqueca, iniciação fraterna, negociações empresariais, } \\
\text { almoços de trabalho } \\
\text { Refeições, hora de dormir, celebrações de aniversários e } \\
\text { feriados }\end{array}$ \\
\hline Metas e emoções individuais & Pessoal & Cuidados pessoais, rituais domésticos \\
\hline Biologia & Animal & Saudação, acasalamento \\
\hline
\end{tabular}


Uma visão mais ampla do ritual reconhece que as atividades rituais operam em contextos não religiosos e que elementos místicos estão presentes em situações não religiosas. Apesar das ênfases secular e racional das culturas pós-industriais, as pessoas de hoje ainda se agarram a superstições e muitas vezes parecem fortemente motivadas por elas, como descobriu recentemente a Procter and Gamble, quando surgiu um forte boato que a ligava a Satã, citando como evidência um simbolismo satânico oculto no logo da P\&G. Essa fofoca religiosa aparentemente inacreditável custou à empresa milhões de dólares em vendas perdidas, contencioso judicial e custos de design de uma nova logomarca. Não obstante a carência de evidências empíricas convincentes, muitas pessoas ainda investem em seus números da sorte (loterias, apostas em cavalos), dão preferência a roupas "sortudas" (uniformes esportivos, um "terno poderoso") e invocam procedimentos para dar sorte (rimas recitadas à mesa de dados). Crenças arbitrárias como essas são muitas vezes encenadas em representações rituais. A superstição surge também em histórias folclóricas modernas que são passadas adiante, por vezes de forma ritualística, como parte da tradição oral de uma cultura (Sherry, 1984).

Se a transcendência é uma das características dos rituais de base cosmológica, diversas formas de experiência estética se qualificam como uma categoria separada de comportamento ritual. Bocock (1974) interpreta os rituais estéticos como um desalojamento de impulsos religiosos por práticas seculares. Diversos produtos estéticos (ópera, sinfonia, teatro) são comumente considerados espiritualmente elevados e seu consumo é altamente ritualizado (Levy, Czepiel e Rook, 1981). Mesmo situações estéticas menos elevadas, como um concerto de heavy metal, são episódios extensamente ritualizados.

Os valores e processos culturais constituem outra fonte primária de comportamento ritual. Uma categoria de fenômenos rituais foi rotulada pelos antropólogos como ritos de passagem (Gennep, 1908). Esse tipo de ritual gira em torno da observação social de eventos que marcam simbolicamente as mudanças do status social dos indivíduos. Foram identificadas grandes categorias de ritos, que marcam a gravidez e o nascimento, a iniciação dos adolescentes na idade adulta, o noivado e o casamento, e o funeral. Os ritos de passagem são dispositivos simbólicos que acentuam a natureza permanente de uma mudança de status (Mol, 1976, p. 239). Esse tipo de comportamento coletivo e simbólico é um dos principais focos de grande parte da pesquisa antropológica sobre culturas pré-modernas (Turner, 1969). O lugar dos ritos de passagem formais no mundo pós-industrial de hoje é controverso, mas os estágios de desenvolvimento da vida da pessoa média ainda estão ligados por uma série razoavelmente previsível de experiências rituais: circuncisão, batismo, crisma, formatura, alistamento militar, casamento(s), divórcio(s), aposentadoria e funeral.

Muitos entendem que os rituais públicos contribuem para a coesão social (Leach, 1968; Munn, 1973). O ritual também é interpretado como um meio eficaz para regular conflitos sociais (Levy e Zaltman, 1975). O ritual é uma linguagem social (Levi-Strauss, 1962) que define a maneira certa de agir (Bossard e Boll, 1950) e fornece uma codificação social de experiências (Firth, 1973). Os rituais fazem declarações simbólicas sobre a ordem social dramatizando mitos culturais (Campbell, 1972; Harrison, 1912) e ligam o presente ao passado (Durkheim, 1912). A análise histórica que Daniel Boorstin (1973) faz da cultura americana mostra, com numerosos exemplos, como surgiram no campo e nas cidades diversos rituais para ligar uma nova nação por meio de um conjunto comum de práticas simbólicas.

Alguns observadores contemporâneos detectam um declínio dos rituais sociais comuns e interpretam isso como um grave problema social (Douglas, 1974), É certo que alguns rituais sociais tornaram-se relativamente vazios e desprovidos de significado, e são hoje meramente ritualísticos (Erikson, 1977). Por outro lado, embora a popularidade de algumas ocasiões rituais tenha caído, emergiram novos rituais para tomar seu lugar, se não para substituí-las. Nos Estados Unidos, o relativamente novo Domingo do Super Bowl é uma das maiores celebrações ritualizadas do mundo e a participação nas festividades de São Patrício parece crescer a cada ano. O fato de alguns rituais haverem perdido ou estarem perdendo importância não significa que todos os rituais estejam em declínio. Como a maioria dos produtos do mercado, os rituais estão igualmente sujeitos às forças do ciclo. Também é útil reconhecer como as forças de segmentação deram origem a rituais que atraem público cada vez menor, como, por exemplo, o ressurgimento de rituais étnicos a partir do caldo cultural americano.

Os rituais cívicos invocam temas de inclusão (ou exclusão) comunitária e social, e dependem de veículos simbólicos como hinos nacionais, juramentos, paradas e cerimônias de celebração. Tais eventos geralmente também envolvem o uso extensivo de artefatos rituais, como bandeiras, vestimentas, arranjos florais e alimentos. A análise que Warner (1959) faz da parada do Memorial Day (homenagem aos soldados mortos na II Guerra Mundial) dos Estados Unidos exemplifica o estudo antropológico de um proeminente ritual cívico. No nível 
dos grupos menores, muitas práticas rituais permeiam o dia-a-dia, do Dia da Panqueca dos Elks aos almoços de trabalho formais, passando por rituais de negociação empresarial. Até uma ida ao McDonald's é interpretada como um ritual social contemporâneo (Curry e Jibou, 1980; Kottak, 1978).

A família é a fonte de numerosos e variáveis rituais que animam as refeições, a hora de dormir e as comemorações de aniversários e feriados. Quase qualquer atividade doméstica pode ser ritualizada: de fato, alguns observadores vêem a presença ou ausência de sistemas rituais familiares como índice confiável da saúde social de uma família (Bossard e Boll, 1950).

Além das forças externas que dão origem a diversos fenômenos rituais, há a psique individual, também rica fonte de comportamento ritual. Interpretações psicológicas dinâmicas tendem a retratar o comportamento ritual como defesa contra a impulsividade, exigindo renúncia a instintos socialmente danosos (Freud, 1959, 1962) e, de modo mais geral, "mantendo afastados os perigos do inconsciente" (Jung, 1959, p. 22). Agindo como mais que medidas preventivas, os rituais oferecem benefícios ao contribuírem para a individuação da pessoa (Jung, 1958, p. 273) e levando a um desenvolvimento sadio do ego (Erikson, 1982, p. 73). Práticas rituais individuais são comuns nos cuidados pessoais diários e em diversas atividades domésticas. Essas práticas emprestam estrutura e significado à mais mundana das atividades. Por outro lado, se essas práticas se tornam por demais restritivas, podem representar neuroses, como rituais de lavagem compulsiva das mãos.

\section{AVALIAÇÃO DA VITALIDADE DO RITUAL}

Entre as dúzias de ocasiões rituais públicas que ocorrem ao longo do ano, há considerável variação quanto ao vigor de sua observação. Alguns rituais ainda recebem atenção, enquanto outros são relativamente ignorados e muitos se encontram em estado incerto. O ritual do Ano-Novo pode ser celebrado com diversos artefatos dentre uma ampla parafernália: matracas e fogos, chapéus de festa, serpentinas, champanhe, todos chegando ao clímax na familiar cerimônia da "contagem regressiva”. Mas até mesmo esse popular evento ritual é caracterizado por um grau de incerteza quanto ao roteiro e aos papéis. As pessoas freqüentemente expressam certa confusão quanto ao fato de o Ano-Novo dever ser recebido em casa ou num ambiente público. Alguns escolhem não participar das festividades de réveillon, optando pela maratona ou pelos jogos de futebol americano do dia seguinte, e/ou por visitar amigos próximos e parentes. Por outro lado, a observação de diversos rituais americanos tradicionais declinou rapidamente no decurso de poucas gerações. É o caso do $1^{\circ}$ de Abril, do $1^{\circ}$ de Maio, do Dia do Trabalho e do Aniversário de Lincoln. Outros rituais tradicionais dão sinais de popularidade crescente: o Dia de São Patrício, casamentos formais e o Natal. E surgem regularmente novos rituais: festas de tupperware, degustações de vinho, sessões de aeróbica, o Domingo do Super Bowl e o Aniversário de Elvis Presley.

É possível avaliar a vitalidade de qualquer ritual a partir dos elementos estruturais identificados anteriormente. O Quadro 2 resume a avaliação de quatro ocasiões rituais exemplares em termos dos seguintes critérios:

1. Natureza e extensão do consumo de artefatos.

2. Presença ou ausência de roteiro bem definido do ritual.

3. Clareza da percepção que os participantes têm de seus papéis.

4. Presença ou ausência de público-alvo bem definido além dos participantes imediatos.

Uma de três pontuações possíveis é atribuída a cada dimensão: "+" denota que uma determinada dimensão é claramente definida e vigorosa, "?" representa um estado geralmente incerto e "-" indica condição relativamente deteriorada.

Usando esses critérios, o Natal é avaliado como uma ocasião ritual vigorosa. Embora sua celebração já tenha sido proibida na Nova Inglaterra puritana (Barnett, 1946), o Natal é observado publicamente em grande parte da cultura ocidental, com envolvimento intenso de milhões de famílias americanas. O grosso do faturamento anual de diversos setores depende dos extensos rituais de troca de presentes e do uso generalizado de símbolos rituais (como luzes e bolas coloridas, visgo, guirlandas e coroas, representações de Papai Noel). Os rituais de Natal também prescrevem o consumo de alimentos e bebidas especiais em ocasiões de cerimônia. Mas até o ritual de Natal tem sofrido mudanças, apresentando alguns sinais de incerteza quanto a roteiro e papéis. As pessoas que não freqüentam habitualmente a igreja tendem a experimentar certa ansiedade quanto à visita anual prescrita. O número crescente de lares individuais e famílias de múltiplos casamentos dá origem a incerteza e conflito quanto à localização prescrita do ritual, à combinação de participantes e às normas de troca de presentes. Além disso, elementos de roteiro como cantar canções de Natal 
de porta em porta [carolling] parecem estar desaparecendo do cenário urbano moderno.

O status do Dia das Bruxas enquanto ritual é mais ambíguo. A maioria das pessoas está familiarizada com seus artefatos rituais - fantasias, doces, fantasmas e duendes, as cores laranja e preto - mas o roteiro do Dia das Bruxas não é bem definido. A atividade de guloseimas ou travessuras está sob cerco já há alguns anos, e os pais adotaram uma atitude de cautela. As crianças ainda vão a festas à fantasia na escola e em casa, mas bailes de máscaras para adultos são menos freqüentes. Em última análise, não está claro se o Dia das Bruxas é voltado principalmente para um público adulto ou infantil (Stone, 1959), uma vez que rituais sérios de Dia das Bruxas podem ser tanto assustadores quanto debochados. (Tanto o Dia das Bruxas quanto o Natal representam rituais que passaram de uma arena estritamente religiosa para outra, mais secular. Para muitos participantes, a superestrutura material domina os elementos espirituais.)

$\mathrm{O} 1^{\circ}$ de Maio americano representa um ritual que está bastante deteriorado. Poucos hoje dançam com fitas coloridas em torno de um mastro nessa festa da primavera [May Day]; e até seriam considerados esquisitos se o fizessem. Não há muitas crianças entregando secretamente cestas de flores e doces na casa de seus amigos, apesar da criatividade e do prazer proporcionados por essa atividade clandestina. A observação ritual do $1^{\circ}$ de Maio nos Estados Unidos praticamente desapareceu, tendo sido sua celebridade ironicamente deslocada pelos símbolos militares e agressivos de um outro ritual no mesmo dia, o comunista.1 Talvez a cultura urbana dos Estados Unidos de hoje não encontre mais sentido nesse antigo rito de fertilidade, ou talvez a sina do $1^{\circ}$ de Maio represente um caso de marketing deficiente.

As cerimônias de formatura representam o tipo de situação em que o roteiro, os papéis e a platéia do ritual são bem articulados, mas a dimensão de artefatos é menos explicitamente prescrita. Enquanto o diploma certifica uma mudança de status, não há um presente específico que goze de status proeminente enquanto marcador da formatura. Além disso, embora seja comum haver festas após a colação de grau, elas não são regidas pela roteirização explícita de rituais como recepções de casamento ou jantares de aposentadoria. Essa situação é semelhante à dos aniversários de casamento: os participantes estão claramente identificados, mas seus respectivos papéis e os requisitos de troca de artefatos não estão explicitamente definidos. Belk (1979) fornece algumas evidências para demonstrar como as categorias de preço dos presentes são afetadas pelo tipo de ocasião e pelo recipiente. Seus resultados sugerem que os consumidores compartilham de algumas idéias comuns a respeito de situações de troca de presentes, mas que ainda há grande variação quando se trata do roteiro, papel e dos detalhes dos artefatos. Quando essa variação se torna extrema, a vitalidade de um ritual pode diminuir. Mas não necessariamente, já que uma celebração idiossincrática de aniversário pode representar uma experiência ritual vital para as pessoas envolvidas. Porém, se houver baixo consenso social quanto à observação de um ritual, sua vitalidade a longo prazo pode estar ameaçada.

\section{SIGNIFICADO DO RITUAL}

A vitalidade de qualquer ritual tende a diminuir quando os participantes deixam de considerá-lo significativo. Embora o significado simbólico de muitos rituais públicos de grande porte seja freqüentemente óbvio, o significado de rituais pessoais individuais pode ser mais evasivo. A maioria das interpretações do comportamento ritual é bastante particular: explica como o ritual opera dentro de ambientes específicos: em famílias (Bossard e Boll, 1950), ritos de passagem (Gennep, 1908), vida co-

\section{Quadro 2 - Avaliação de vitalidade dos rituais}

\begin{tabular}{|l|c|c|c|c|}
\hline \multicolumn{1}{|c|}{} & \multicolumn{3}{c|}{ OCASIÃO RITUAL } \\
\hline DIMENSÃO DE AVALIAÇÃO & NATAL & DIA DAS BRUXAS & $1^{\circ}$ DE MAIO & FORMATURA \\
\hline Artefatos rituais & + & + & $-/ ?$ & $?$ \\
\hline Roteiro do ritual & + & $?$ & $?$ & + \\
\hline Papel no ritual & + & + & - & + \\
\hline Platéia do ritual & + & $?$ & - \\
\hline
\end{tabular}

Nota: + = Bem definido, vigoroso

$?=$ Status incerto.

$-=$ Fracamente definido, fraco. 
munitária (Warner, 1959), ou mesmo o salão de beleza moderno (Ewen, 1979). O psicólogo Erik Erikson (1977, 1982) oferece uma explicação distintamente universal ao sugerir que todo comportamento ritual está enraizado na psique humana. A teoria de Erikson conecta diretamente expressões rituais públicas e de grande porte ao desenvolvimento individual de comportamentos ritualizados rotineiros. Ele argumenta que embora um grande evento ritual, como um rito de passagem, represente um anúncio público do novo status de um indivíduo, é por meio das atividades rituais diárias que essa mudança é simbolicamente reforçada. Por exemplo, a festa de debutante de uma garota simboliza tradicionalmente sua transição social da infância para a idade adulta; mas esse evento ritual, por si só, não realiza uma transformação instantânea. Em vez disso, é nos rituais diários, como os que giram em torno dos cuidados pessoais ou rotinas do namoro, que o novo status social é funcionalmente apresentado.

Erikson interpreta o ritual como um comportamento essencialmente integrador, e sua análise parte de suas teorias psicossociais do desenvolvimento humano. Mais do que Freud, Erikson enfatiza a pressão das forças sociais externas sobre o desenvolvimento da psique humana. Enxerga todo o desenvolvimento humano como um processo seqüencial de oito estágios (Erikson, 1951). Cada estágio apresenta ao indivíduo uma "crise" psicossocial distinta. O grau de sucesso que o indivíduo tem na solução de cada uma dessas crises de desenvolvimento se reflete, em última análise, na saúde ou patologia relativa da personalidade adulta. Finalmente, cada crise é caracterizada por um elemento temático distinto que energiza tanto o comportamento ritualizado diário quanto os rituais públicos de maior porte. Os rituais de cuidados pessoais diários de uma jovem, por exemplo, são motivados pelas mesmas forças psicossociais que geram os bailes e as festas formais de debutante que a "apresentam" à sociedade e marcam sua transição para o status sexualmente disponível.

As relações entre (1) os estágios de desenvolvimento pessoal, (2) as crises psicossociais e os temas rituais que distinguem cada estágio e (3) as arenas do mercado em que esses temas são representados de maneira mais proeminente encontram-se resumidas no Quadro 3. Rituais de temas numinosos (místicos) originam-se da crise de confiança da infância. O desenvolvimento sadio da personalidade depende de a criança confiar em um "outro primal" (Erikson 1982, p. 45) que inicialmente é a mãe e depois assume uma identidade cosmológica (deus, a força) na vida do indivíduo. Uma resolução malsucedida da crise produz uma personalidade desconfiada e as conseqüentes visões negativas do cosmo e da vida em geral. Segundo Erikson, essas perspectivas se traduzem na arena pública, onde há variação consideravelmente menor do grau com que diferentes rituais místicos expressam a esperança e a confiança.

Erikson relaciona as crises do início da infância a uma área totalmente diferente da experiência ritual: a lei e a or-

Quadro 3 - Significado do ritual: um modelo eriksoniano

\begin{tabular}{|c|c|c|c|}
\hline ESTÁGIO DE DESENVOLVIMENTO & CRISE PSICOSSOCIAL & ELEMENTOS TEMÁTICOS DO RITUAL & ÁREA DO MERCADO \\
\hline Lactância & Confiança $\mathrm{x}$ desconfiança & Numinoso & $\begin{array}{l}\text { Religião } \\
\text { Superstição } \\
\text { Sorte/azar }\end{array}$ \\
\hline Primeira infância & Autonomia $\mathrm{x}$ vergonha & Judicioso & Lei e ordem \\
\hline Idade de brincar & Iniciativa $\mathrm{x}$ culpa & Dramático & $\begin{array}{l}\text { Teatro } \\
\text { Brinquedo }\end{array}$ \\
\hline Idade escolar & Atividade $\mathrm{x}$ inferioridade & Representativo & Tecnologia \\
\hline Adolescência & Identidade $\mathrm{x}$ difusão & Ideológico & Ideologia \\
\hline Juventude & Intimidade $\mathrm{x}$ isolamento & Associativo & $\begin{array}{l}\text { Parceria } \\
\text { Carreira } \\
\text { Organizações }\end{array}$ \\
\hline Idade adulta & Produtividade $\mathrm{x}$ estagnação & Geracional & $\begin{array}{l}\text { Educação } \\
\text { Tradição }\end{array}$ \\
\hline Velhice & Integridade $\mathrm{x}$ desesperança & Filosófico & $\begin{array}{l}\text { Sabedoria } \\
\text { Filosofia }\end{array}$ \\
\hline
\end{tabular}


dem. O período de treinamento sanitário das crianças simboliza a crise básica entre autonomia, de um lado, e vergonha e dúvida, de outro. Os rituais desse período têm por objetivo instruir as crianças nos "sims" e "nãos" elementares, e na diferenciação entre certo e errado. A aceitação e interiorização normais desses padrões geram autopercepções de independência e legitimidade, ao passo que o fracasso freqüentemente produz patologias compulsivas. Erikson interpreta esse estágio de desenvolvimento como fonte dos elementos de julgamento do comportamento ritual adulto e das estruturas morais e rituais correspondentes do sistema judicial.

Não é necessário elaborar cada elemento do arcabouço de Erikson para identificar as diversas forças teóricas que distinguem sua interpretação do comportamento ritual. Primeiro, ela esclarece a significância dinâmica das experiências ritualizadas diárias do indivíduo relacionando-as com os eventos rituais públicos de maior porte. Embora essas ocasiões grandiosas forneçam expressão dramática pública, o trabalho simbólico real pode ser feito em menor escala por meio da ritualização diária da experiência individual. Segundo, a teoria de Erikson relaciona o comportamento ritual adulto às experiências infantis individuais, e é justamente por isso que os rituais são significativos e envolventes: ligam simbolicamente o presente ao passado. A lógica de Erikson e o título de seu livro, Toys and Reasons ("Brinquedos e razões"), refletem o ditado popular segundo o qual a diferença entre os homens e os meninos está no preço dos seus brinquedos. Adultos e crianças não são espécies separadas; a vida adulta se baseia nas experiências infantis.

Um terceiro ponto forte da teoria de Erikson é o grau em que se baseia no conflito. Seu modelo de crise reconhece as dificuldades existentes na experiência individual de lidar com as demandas das forças sociais externas. Grande parte da pesquisa sobre consumidores deixa de reconhecer as dimensões de conflito e ambivalência que caracterizam diversos aspectos do comportamento no mercado (Levy e Zaltman, 1975). O modelo de Erikson é mais realista porque retrata o comportamento humano de forma mais dinâmica do que a maioria dos modelos existentes de comportamento. Erikson percebe que muitos indivíduos não resolveram com sucesso suas crises de desenvolvimento. Esse fracasso gera sentimentos como desconfiança, vergonha, culpa, inferioridade e isolamento. A maior parte da pesquisa contemporânea sobre consumidores dá pouca atenção a esses sentimentos negativos e não percebe inteiramente como eles afetam o comportamento do consumidor.

\section{UM ESTUDO EXPLORATÓRIO SOBRE OS RITUAIS DE CUIDADOS PESSOAIS DOS CONSUMIDORES}

Os pesquisadores de hoje raramente retratam o comportamento do consumidor com a complexidade rica e dinâmica dada por Erikson. Mas se em boa parte comprar e consumir são, de fato, atos ritualizados, e se o comportamento ritual é tão intensamente motivador quanto sugerem Erikson e muitos outros, então muitos rituais comuns domésticos e de mercado são mais do que hábitos automáticos. Até os rituais diários, como os que estão associados aos cuidados pessoais, envolvem emoções e aspirações profundas. A discussão a seguir apresenta resultados selecionados de dois estudos exploratórios concebidos para sondar o conteúdo psicossocial e de artefatos dos rituais matutinos de cuidados pessoais de jovens adultos. Os resultados apresentados não pretendem ser generalizações sobre a população de adultos jovens em geral; em vez disso, são oferecidos como exemplos da natureza e da profundidade de sentimento que distinguem o comportamento ritual, e como sugestões de alternativas metodológicas para a investigação de tais fenômenos. Ao se visar o comportamento individual de cuidados pessoais, deu-se atenção especial ao cuidado e à manutenção do cabelo, não ao processo de cuidados pessoais como um todo.

\section{Estudo 1: Atividade ritual de cuidados pessoais}

A atividade humana de cuidados pessoais não é apenas higiênica, pois também age sobre o corpo modificando a cor, o odor, o tamanho aparente e o formato do próprio corpo (Holman, 1981). O comportamento de cuidados pessoais é literalmente uma linguagem corporal, comunicando mensagens específicas sobre o status social, a maturidade, as aspirações, a conformidade e até a moralidade do indivíduo. Os cuidados pessoais humanos foram extensamente interpretados como comportamentos rituais (Ewen, 1979; Hope, 1980; Miner, 1956; Wax, 1959). No núcleo da maioria dos rituais de cuidados pessoais estão diversos processos de limpeza, corte, modelagem e hidratação dirigidos ao cabelo (Vlahos, 1979). Esse primeiro estudo tem três propósitos: (1) descrever seletivamente o conteúdo de artefatos dos rituais matinais de cuidados pessoais dos entrevistados, (2) medir seus níveis de autosatisfação e (3) identificar suas frustrações com as rotinas de cuidados com o cabelo.

\section{Metodologia}

Os entrevistados preencheram um longo questionário concebido para investigar amplamente as atividades, idéias, atitudes e preocupações que energizam seus rituais de 
cuidados pessoais. Boa parte do questionário era autoaplicada, embora algumas respostas tenham sido obtidas por meio de entrevistas pessoais. Em alguns casos, os entrevistados receberam a quantia de 5 dólares por sua participação. A amostra abrangeu 91 pessoas ( 44 homens e 47 mulheres), selecionadas em salas de aula de faculdade e em diversos ambientes, inclusive em um centro de assistência social, shopping centers e alojamentos estudantis. Os entrevistados foram selecionados em proporções aproximadamente eqüitativas dentre populações das classes operária $(n=24)$, média baixa $(n=29)$ e alta $(n=34)$. O status social foi medido por meio do Índice de Características de Status de Warner (1949) combinado com o grau de escolaridade dos entrevistados e com informações sobre as ocupações de seus pais. Isso foi feito para controlar o fato de que os históricos de status social dos estudantes universitários são muitas vezes mal medidos por renda, residência e ocupação. A idade dos entrevistados variou entre 18 e 25 anos $(m=22,3 ; d p=3,79)$. Na discussão de alguns dos resultados da pesquisa, os protocolos dos entrevistados são identificados entre parênteses pelo sexo e pela idade imediatamente após cada citação.

\section{Resultados}

As atividades de cuidados com o cabelo ocupam o centro dos roteiros de cuidados pessoais dos jovens adultos da amostra, e numerosos artefatos são usados em suas representações diárias do ritual. Quase dois terços afirmaram que sempre ou normalmente lavam o cabelo com xampu pela manhã; muitos que não o faziam pela manhã (principalmente mulheres) afirmaram fazê-lo à noite para adiantar-se na manhã seguinte. Além disso, quase metade dos entrevistados indicou que sempre ou normalmente aplica condicionador como parte da rotina matutina de cuidados pessoais. Pouco mais de um terço da amostra indicou tendência ao uso de secador de cabelo pela manhã. Um produto para cuidar do cabelo - laquê - caiu de moda no grupo amostrado (pelo menos pela manhã); apenas $8 \%$ relataram usar regularmente o produto. Dois outros produtos de cuidados pessoais - óleo para o cabelo e xampu anticaspa - são usados regularmente por apenas 4\% da amostra. Evidentemente, há outros artefatos que podem ajudar nos rituais de cuidados capilares, mas esta amostra não se dedica ao uso idiossincrático de produtos ou em produtos que sejam (relativamente) livres de ambigüidade quanto ao gênero.

A pesquisa procurou em seguida descobrir como os jovens adultos efetivamente se sentem em relação ao próprio cabelo. Quando interrogados diretamente, os entrevistados indicaram se sentir absoluta e relativamente satisfei- tos com o próprio cabelo. Os estudantes preencheram a Body Cathexis Scale, que, em 26 itens (Secord e Jourard, 1953), perguntava o quanto estavam satisfeitos com suas várias características corporais, classificando-as segundo uma escala do tipo Likert de cinco pontos. Dos 26 itens medidos, o cabelo teve os melhores resultados em termos de satisfação geral: $82 \%$ da amostra declararam ter sensação positiva ou altamente positiva quanto ao cabelo. A aparência dos olhos e a dos órgãos sexuais ficaram em segundo e terceiro lugares, respectivamente, em satisfação, enquanto a cintura foi o item de menor satisfação percebida (apenas $44 \%$ de positivos ou altamente positivos), seguida de perto pelos joelhos e pelas unhas dos pés. Esses resultados sugerem que os jovens adultos pesquisados devem energizar seus rituais de cuidados capilares com um entusiasmo otimista, mas tal interpretação é turvada pelas conclusões de outra pergunta da pesquisa, concebida para sondar menos diretamente o afeto pelos cabelos.

Pediu-se aos entrevistados que considerassem todos os seus procedimentos diários de cuidados pessoais e selecionassem a atividade que mais lhes trazia frustração. Os cuidados com os cabelos foram o mais citado por uma margem substancial, e as reclamações foram manifestadas com emoção em alguns casos. Muitas reclamações se concentravam em quanto tempo levavam para arrumar o cabelo, como exemplificam esses protocolos modais:

Arrumar o cabelo é a parte mais difícil. Passo horas HORAS, mesmo! - arrumando o cabelo. ISSO ME DEIXA LOUCA! (mulher-20)

Detesto secar o cabelo. Leva muito tempo porque é muito comprido. (mulher-21)

Talvez por causa da diferença contemporânea entre sexos quanto ao comprimento do cabelo e por causa de regras rigorosas quanto à aparência pessoal, reclamações sobre o tempo gasto foram mais encontradas entre as mulheres entrevistadas. Mas a frustração central com os cuidados com o cabelo não tem tanto a ver com o tempo gasto por si só quanto com os resultados desapontadores obtidos apesar de esforços prodigiosos. Essa idéia foi manifestada vigorosamente tanto pelos homens quanto pelas mulheres da amostra.

Detesto arrumar meu cabelo, secá-lo por 20 minutos, porque nunca fica do mesmo jeito duas vezes. (mulher-24)

Detesto ter todo o trabalho de lavar e secar meu cabelo e ver que às vezes ele fica uma droga quando termino. (homem-20) 
Essas frustrações parecem inteiramente plausíveis; qualquer pessoa pode ficar agitada quando as coisas não saem como se planejou. Mas a frustração com os cuidados pessoais às vezes é mais profunda do que o mero desapontamento com um procedimento que deu errado. O comportamento de cuidados pessoais dos jovens adultos envolve mais do que simplesmente se limpar porque é motivado por poderosas forças convergentes: as crises psicossociais da identidade individual e da intimidade interpessoal (Erikson, 1951, 1977), as rígidas normas de aparência do narcisismo entre pares e a pressão vocacional de se ter a aparência certa. Como preveria a interpretação de Erikson (1977), o comportamento ritual de cuidados pessoais envolve sentimentos tanto negativos e ambivalentes quanto positivos. Embora os resultados desse estudo forneçam algumas evidências desses elementos, as conclusões não apresentam muita profundidade em termos de conteúdo. Isso se deve, em grade parte, às limitações inerentes ao projeto da pesquisa por meio de auto-relato direto.

\section{Estudo 2: Temas de fantasia do ritual de cuidados pessoais}

Embora o ritual seja uma forma de linguagem corporal, seu vocabulário pode ser relativamente inconsciente, e a fala discursiva a seu respeito tende a confundir (Bird, 1980; Caplow, 1984). Para entender melhor o conteúdo psicossocial dos rituais de cuidados pessoais de jovens adultos aqui estudados, foi administrado um Teste de Apercepção Temática (TAT) especialmente desenhado. Essa abordagem admite que alguns itens da agenda do ritual possam estar relativamente ocultos. Uma técnica expressiva e criativa como o TAT encoraja os entrevistados a baixar as defesas e projetar seu próprio material psicológico em personagens e situações imaginários (Levy, 1986; Murray, 1938). Quando interrogadas diretamente, as pessoas podem não estar realmente cientes de suas motivações e emoções em relação aos cuidados pessoais, e suas explicações podem ser meras racionalizações. Além disso, também podem relutar em discutir abertamente tópicos normalmente considerados provados e sensíveis. Uma abordagem projetiva tem o potencial de superar essas barreiras à comunicação.

\section{Metodologia}

Foram escolhidas, com base nos critérios de avaliação sugeridos por Henry (1956) e Murstein (1963), duas figuras de estímulo para o Teste de Apercepção Temática de Cuidados Pessoais (GTAT - Grooming Thematic Apperception Test). Os dois estímulos do GTAT eram as figuras de: (1) uma mulher, entre jovem e de meia-idade, com bóbis e aplicando maquiagem, e (2) um jovem usando um secador de cabelos. Presumia-se que esses símbolos fossem de familiaridade quase universal entre a população de adultos jovens. A hipótese projetiva (Rappaport, 1942) sugere que as histórias imaginativas dos entrevistados, articuladas em resposta ao estímulo pictórico, revelarão aspectos inconscientes e outros ocultos de seu comportamento ritual de cuidados pessoais. As figuras de estímulo do GTAT encorajaram os entrevistados a concentrar-se em questões ligadas aos cuidados pessoais.

Participaram do estudo 51 jovens adultos (31 mulheres, 28 homens) recrutados em salas de aula e em outros ambientes. Os entrevistados foram selecionados em proporções aproximadamente uniformes das populações das classes trabalhadora $(n=20)$, média baixa $(n=19)$ e alta $(n=20)$, usando os critérios de mensuração descritos no primeiro estudo. A idade deles variava entre 19 e 26 anos $(m=21,5 ; d p=3,36)$. As figuras do GTAT lhes foram apresentadas e em seguida eles receberam instruções para escrever histórias criativas e dramaticamente completas sobre as figuras, cada uma com começo, meio e fim, e com personagens identificadas. As histórias dos entrevistados variaram entre 175 e 250 palavras, geralmente satisfazendo o critério largamente aceito de 200 palavras para identificação de envolvimento do entrevistado (Murstein, 1963), e foram escritas entre 35 e 60 minutos. Todas as histórias foram colhidas por meio de auto-aplicação, com exceção de alguns entrevistados com habilidades de escrita insuficientes; essas foram colhidas verbalmente.

\section{Resultados}

Para orientar a construção de suas histórias imaginárias, pediu-se aos entrevistados que fornecessem uma identidade à única personagem visível em cada figura de estímulo. A maioria lhe deu pelo menos um prenome, e muitos forneceram minuciosos detalhes demográficos e psicográficos, indicando idade, status econômico, profissão, aspiração pessoal, comportamento sexual e diversas informações sobre seu estilo de vida. Os jovens adultos aparentemente não precisam de muito estímulo para entrar no reino fantástico da experiência.

Projeções de identidade. O homem de secador de cabelos é normalmente considerado jovem - algo entre $16 \mathrm{e}$ 25 anos de idade. Além disso, há pouca concordância sobre o tipo de pessoa que é. Para alguns, é um cara como qualquer outro, alguém que está se arrumando depois do trabalho ou de fazer exercícios. Algumas histórias elevam sua personagem a um status de modelo: um gerente ou profissional liberal, um atleta, ou um solteirão sofisticado. Outras histórias inflam esses papéis até atingirem propor- 
ções heróicas: um magnata internacional, um superastro dos esportes e um atleta sexual. O padrão imaginário da mulher de bóbis é estruturalmente semelhante. Ela é descrita como estando entre os 20 anos e a meia-idade. É freqüentemente imaginada como dona-de-casa, executiva de baixo escalão ou estudante universitária. Essas imagens são geralmente positivas, e nessas histórias os cuidados pessoais da mulher estão associados a resultados desejáveis.

Por outro lado, várias histórias retratam as personagens principais como os fracassados incuráveis e completos nerds sem realizações e constantemente frustrados em suas vidas românticas. Mais extremadas são as representações das personagens de estímulo como marginais (alcoólatras ou viciados em drogas), delinqüentes (que abandonaram a escola, prostitutas, punks ou motoqueiros) ou transviados (psicóticos, homossexuais, transexuais).

Paralelamente a essas variações de identidade, o conteúdo dramático das histórias vai de roteiros socialmente convencionais (preparação para encontros ou para o trabalho, cuidados após o esporte) a temas incomuns e altamente fantásticos (alucinações, homicídio, viagem espacial). Esses resultados não implicam necessariamente que os jovens adultos pesquisados se identifiquem diretamente com as personagens e situações que descrevem, ou aspirem a elas, embora possa ser provavelmente o caso de alguns. Em vez disso, suas construções temáticas refletem preocupações intensas. Poucos rituais estão tão fortemente ligados à crise de identidade psicossocial quanto os rituais diários de cuidados pessoais, de modo que não surpreende que as fantasias dos entrevistados a respeito desse tema reflitam sua consciência de possibilidades de identificação tanto positivas quanto negativas.

Ruptura. Contrastando com a grande variação quanto à identidade imaginada de cada personagem de estímulo, houve considerável consenso quanto às importantes questões psicossociais da agenda de cuidados pessoais. Os entrevistados por vezes descreveram uma pessoa ativa e de responsabilidade. O homem de secador de cabelos se ocupa fechando negócios ou vencendo jogos de futebol com passes no último minuto. Esse cara faz e acontece. A mulher foi às vezes imaginada como um dínamo dos negócios ou como a dona-de-casa perfeita. Ela também pode ser uma estudante dominadora que estabelece as regras em seus relacionamentos interpessoais. Por outro lado, com quase igual freqüência, as personagens foram imaginadas como menos independentes, pessoas que estavam apenas tentando evitar problemas. O jovem vive com os pais e é o bode expiatório da família; seus professores o perseguem na escola. Às vezes ele se esconde em seu quarto, ou recorre à bebida ou às drogas. Pode tentar escapar de quem o atormenta fugindo de casa ou do trabalho, mas freqüentemente sai perdendo frente a seus inimigos. A mulher foi descrita como dominada por seu chefe ou marido, lutando por independência e respeito. Essas diversas percepções lançam luz sobre os conflitos internos que acompanham a luta dos jovens adultos por autonomia pessoal e ilustram como os entrevistados projetam suas preocupações nos temas do ritual de cuidados pessoais.

As histórias também revelam como os artefatos de cuidados pessoais estão investidos de significado ritual. $\mathrm{Na}$ batalha pela independência, o secador de cabelos é uma arma simbólica. Dá ao jovem o poder de imitar as normas de aparência de seus pares e afirmar-se com confiança no cenário social. A última moda pode ir contra a orientação mais tradicional dos pais, mas mesmo cuidados pessoais convencionais podem estar ligados a alguma rejeição dos pais ou de outra figura de autoridade:

Jim deveria ficar em casa para estudar esta noite, mas mesmo assim está se preparando para sair. Ele espera encontrar belas garotas e quer que seu cabelo esteja do jeito certo. (homem-20)

Esteja o jovem secando o cabelo para obter uma aparência conservadora ou tentando atingir um efeito de punk rebelde, o fato é que se prepara para tornar-se um agente social independente, procurando distanciar-se da regulação dos pais. Simbolicamente, o secador de cabelos é fálico e agressivo; frente à figura de estímulo, as histórias dos entrevistados foram por vezes bastante agitadas. Eles desprezaram o guri deslocado, ou o perturbaram com confrontos interpessoais e, à vezes, sujeitaram-no à violência, em lutas de bêbados. Os bóbis parecem não ser tão potentes simbolicamente, mas são valorizados por suas propriedades transformadoras. Às vezes são objeto de ressentimento por causa do controle social neles implícito.

Colocação vocacional e desempenho. A preocupação dos entrevistados com questões vocacionais representa a convergência da fantasia e da realidade socioeconômica. Os jovens adultos de hoje são muito voltados para a carreira: muitos dos envolvidos neste estudo estavam no início da vida profissional. Temas de trabalho e sucesso são proeminentes em suas fantasias de cuidados pessoais. Quando se constrói um roteiro vocacional, o papel dos cuidados pessoais é freqüentemente descrito como instrumental para o sucesso. Os jovens adultos deste estudo perceberam os resultados práticos dos cuidados pessoais, como ilustram os extratos abaixo: 
Ron estava se preparando para o trabalho, dando a atenção habitual à aparência [...] Mais tarde, seu chefe lhe disse que iria sugerir sua promoção. (mulher-22)

Susan está se preparando para sua primeira apresentação e está muito nervosa. Se tudo correr bem, talvez seu chefe a ajude a conseguir o sinal para comprar um carro novo. (mulher-21)

Joe Hearn levanta-se às 6:30 todos os dias, toma banho e seca o cabelo [...] é um agente do FBI e precisa estar alinhado para não perder o emprego. (homem-25)

As estórias dos entrevistados revelam as imagens que têm do crime e do castigo no que se refere aos cuidados pessoais. Enquanto algumas delas os ligam a recompensas vocacionais (contratos de venda, reconhecimento, bonificações, promoções), outras associam cuidados pessoais insuficientes ao fracasso numa entrevista de emprego, à humilhação profissional ou à perda do emprego. É de se observar, embora não surpreenda que essas histórias muitas vezes são contadas num tom irônico e cômico: o humor é um mecanismo comum para desviar a ansiedade.

Aspirações à intimidade. Mais do que qualquer outro elemento de roteiro, os jovens adultos projetam os rituais de cuidados pessoais como preparação para encontros e relações sexuais. Algumas histórias destacam a ansiedade romântica dos indivíduos:

Rhonda se surpreendeu quando o cara mais bonito da praia se aproximou e a chamou para sair. Enquanto se maquiava, perguntava-se se não seria um sonho. (mulher-20)

Sam está se preparando para sair e tentar se dar bem. Hoje ele vai à balada, pegar uma mulher, talvez duas ou três, levá-las para casa e mostrar-lhes o que andavam perdendo. (homem-22)

Várias estórias descrevem o comportamento de cuidados pessoais como algo que leva diretamente a resultados românticos positivos: a colega de trabalho confessa que estava de olho nele há muito tempo; o encontro "às escuras" vira um namoro firme; o jovem satisfaz seus desejos sexuais. Às vezes as histórias dos entrevistados envolvem a arriscada combinação de trabalho e sexo:

Renee já ficara com quatro vice-presidentes. Nada permanente, mas cada um lhe deu um aumento. Agora ela está planejando conquistar mais um. (mulher-22)
Deve estar fazendo uns $30^{\circ}$ e ainda são 7 da manhã. Quando terminar de secar o cabelo, provavelmente precisarei de outro banho [...] Parece que o secador está a uns $80^{\circ}$ [...] mas, e daí? Quando termino de usar isso, minha aparência fica tão boa! Todas as garotas do trabalho vão querer passar a mão no meu cabelo. (homem-26)

Outros cenários ainda destacam a resistência e ambivalência que os jovens adultos sentem em relação às pressões dos encontros:

Bob não entende por que fez a idiotice de convidar Linda para essa festa. Ela nem era tão legal assim, ou sequer inteligente. E ele nem a achava tão atraente [...] Na verdade, ele nem queria ir à festa. (homem-21)

Embora os temas românticos tenham sido bastante comuns, houve variações observáveis entre os sexos. Os homens se concentravam mais em encontrar mulheres e fazer sexo, enquanto as mulheres davam mais ênfase a relacionamentos e casamento.

Magia ritual. Os jovens adultos parecem bastante dispostos a suspender sua descrença quanto às propriedades miraculosas dos produtos e procedimentos de cuidados pessoais. Não raro, descreveram diversos efeitos dos cuidados pessoais que podem ser caracterizados como magia ritual. Roteiros imaginários retrataram extraordinárias mudanças obtidas por causa de alguma atividade específica de cuidados pessoais: um trabalhador cansado se transforma num dínamo de energia; um elixir faz com que uma garota comum pareça charmosa; um cara comum se transforma num Romeu.

Os entrevistados podem não acreditar realmente nos poderes míticos dos cuidados pessoais, mas não vêem mal se os cuidados pessoais de alguma maneira derem uma mãozinha à sorte. Outro efeito mágico atribuído aos cuidados pessoais decorre de seu papel enquanto energizador psíquico. Os cuidados pessoais são valorizados como mecanismo de superação da introversão, e algumas estórias soam como gritos de guerra tribais com temas de ida à guerra social. Tais exortações internas concentramse como um mantra sobre os sentimentos criadores de confiança e geram a energia necessária para a situação em tela. Curiosamente, essas histórias estão muito próximas dos roteiros de muitos comerciais de produtos de cuidados pessoais.

\section{Discussão}

Até os rituais do dia-a-dia, como os associados aos cuidados pessoais, são psicologicamente complexos e intensos. 
Como sugerem esses dados exploratórios, é um erro imaginar que esse tipo de comportamento altamente envolvente seja meramente um hábito. Uma abordagem de pesquisa projetiva parece útil para avaliar as preocupações rituais dos entrevistados, mas ainda há muitos quebra-cabeças para solucionar. Os resultados aqui apresentados são, em grande parte, as respostas modais dos entrevistados; como interpretar itens de baixa incidência, ou mesmo idiossincráticos? Dados os elementos inconscientes do ritual (Bird, 1980; Caplow, 1984), será que muitos dos temas de baixa freqüência não permanecem latentes? Pesquisas futuras também precisarão investigar como os temas imaginados variam entre segmentos de consumidores, e como elementos temáticos específicos estão relacionados aos comportamentos efetivos de compra e consumo dos consumidores.

\section{CONCLUSÃO}

O extenso envolvimento dos consumidores com rituais desafiam os pesquisadores a conceituar e investigar de novas maneiras os comportamentos no mercado. Algumas discussões recentes criticam a exigüidade dos fenômenos de mercado que os pesquisadores costumam estudar. Há um clamor coletivo por uma perspectiva mais ampla que use construtos novos de pesquisa. O estudo do ritual promete esclarecer alguns dos pontos cegos específicos que foram identificados. Mais especificamente, grande parte da pesquisa sobre o mercado e o consumidor visa exclusivamente às atividades mentais dos objetos de estudo; conseqüentemente, há grandes lacunas nas informações sobre o comportamento efetivo dos consumidores. Holbrook e Hirschman (1982) sugerem que os pesquisadores precisam investigar com maior vigor os aspectos experienciais do comportamento. A expressão ritual é uma linguagem corporal e envolve comportamentos tanto mentais quanto físicos. Assim, solicita estudos observacionais mais diretos das experiências dos consumidores ao escolher, comprar e usar diversos artefatos rituais.

Em segundo lugar, os rituais são freqüentemente sérios e normativos. Na qualidade de representações de mitos sociais e individuais (Campbell, 1972; Levy, 1982), os rituais retratam dramática e simbolicamente os desejos individuais de status social, maturidade e identidade sexual. Alguns rituais de consumo o fazem diretamente: aceitação em alguma organização exclusiva, cerimônias de formatura ou festas de debutantes. Esses são eventos sérios e extraordinários na vida das pessoas, mas muitos rituais diários também são sérios porque regulam a inte- ração social (formação de filas, rituais de saudação e despedida) e prescrevem a maneira "certa" de agir. Idéias a respeito do que é certo e errado são reiteradas por meio de práticas rituais que destacam os aspectos normativos da compra e do consumo, numa área que ainda carece de pesquisa extensiva (Zaltman e Wallendorf, 1977).

A experiência ritual também lança luzes sobre os componentes de profundidade psicológica, conflito e fantasia do comportamento rotineiro. Embora lugar-comum durante a era da pesquisa motivacional (Newman, 1958), o papel das motivações complexas de consumo foi deixado de lado durante o recente período voltado para processos. Mas muitos comportamentos de consumo ainda decorrem em última análise, de motivações profundas. O psicólogo Erik Erikson interpreta o comportamento ritual como decorrente da superstição e da crença na magia, e, em alguns casos, de sentimentos de vergonha, culpa, inferioridade, confusão e isolamento $(1977,1982)$. Essa perspectiva nova e dinâmica contrasta fortemente com os vários modelos comportamentais estáticos e ingênuos que retratam os consumidores como maximizadores de atributos racionais e construtivos. A pesquisa do comportamento ritual também atrai a atenção para o papel da fantasia na vida dos consumidores (Rook e Levy, 1983).

Os sistemas rituais também representam o tipo de comportamento simbólico que há mais de 20 anos tem sido relativamente negligenciado na pesquisa sobre consumidores. A observação crítica de Gardner e Levy (1955) de que o simbolismo do produto é um grande ponto cego do marketing não é menos verdadeira em nossos dais. Apesar do reconhecimento generalizado de que muitos produtos e serviços são estímulos simbólicos (Holman, 1981; Levy, 1959; Solomon, 1983), relativamente poucos trabalhos empíricos investigaram a dinâmica do consumo simbólico. O comportamento ritual é uma linguagem simbólica; aprender como os indivíduos vêm a ritualizar aspectos específicos de seu comportamento no mercado irá complementar trabalhos recentes que revelam quando eles aprendem a decodificar os significados simbólicos dos produtos (Belk, Bahn e Mayer, 1982).

Uma última conseqüência epistemológica do reconhecimento da dimensão ritual do comportamento no mercado deve servir para afrouxar o pensamento paradigmático sobre as metodologias de pesquisa. A maioria da pesquisa sobre consumidores e marketing hoje publicada depende de técnicas de auto-relato em que a interação do pesquisador com seus entrevistados é baixa ou inexistente. As pesquisas de formato fixo, concebidas para processar análises computacionais estatísticas, dominam o campo, com poucas exceções. Tais abordagens profiláticas mal 
arranham a superfície da vida real dos consumidores e põem em risco a relevância de grande parte da pesquisa com eles. Já estudar os comportamentos rituais dos consumidores desafia a comunidade científica a experimentar abordagens mais holísticas e interativas. Por sua própria natureza, grande parte do comportamento ritual convida à observação em campo. Extrair os significados embutidos no comportamento ritualizado pode exigir entrevistas intensivas e abertas. E, em alguns casos, os consumidores podem não entender conscientemente o significado de um ritual, ou não ter acesso direto a esse significado; abordagens indiretas, como as técnicas projetivas, podem se revelar úteis.

\section{NOTA DA REDAÇÃo}

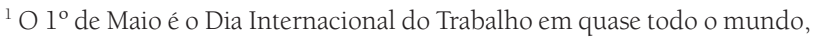
inclusive nos antigos países comunistas, que o comemoravam com uma grande parada militar. Nos Estados Unidos, o Labour Day é comemorado na primeira segunda-feira de setembro.

Este artigo é de propriedade exclusiva da The University of Chicago Press, tanto quanto sua licença de uso, e é protegido pelo Copyright e pelas leis de propriedade intelectual. É um material destinado a uso pessoal e não comercial. Qualquer outro tipo de uso deste artigo é estritamente proibido. O usuário não poderá modificar, publicar, transmitir, participar na transferência ou na venda do material, reproduzir, criar trabalhos dele derivados (inclusive material didático), distribuir, realizar apresentação nem fazer nenhuma utilização do seu conteúdo, inteiro ou em partes. Este artigo foi traduzido objetivando expressamente esta publicação. The University of Chicago Press não assumirá nenhuma responsabilidade por erros de interpretação causados pela tradução. O artigo "The ritual dimension of consumer behavior", do autor Dennis W. Rook, foi originalmente publicado no Journal of Consumer Research, v. 12, n. 3, p. 251-264, 1985, e reproduzido com sua autorização.

\section{REFERÊNCIAS}

ABELSON, R. P. Psychological status of the script concept. American Psychologist, v. 36, n. 7, p. 715-729, 1981.

AYER, A. J. Logical Positivism. Glencoe, IL: Free Press, 1959.

BARNETT, J. H. Christmas in American culture, Psychiatry, v. 9, n. 1, p. $51-65,1946$.
BARNETT, J. H. The American Christmas: A Study in National Culture. New York: Arno Press, 1954.

BELK, R. W. Gift Giving behavior. In: SHETH, J. N. (Ed.). Research in Marketing, ed. JAGDISH N. SHETH, Greenwich, CT: JAI Press, 95-126, 1979.

BELK, R. W.; BAHN, K. D.; MAYER, R. D. Developmental recognition of consumption symbolism. Journal of Consumer Research, v. 9, p. 4-17, 1982.

BIRD, F. The Contemporary Ritual Milieu. In: BROWNE, R. B. (Ed.). Rituals and Ceremonies in Popular Culture. Bowling Green, OH: Bowling Green University Popular Press, 1980. p. 19-35.

BOCOCK, R. Ritual in Industrial Societie. London: Allen and Unwin, 1974.

BOORSTIN, D. J. The Americans: The Democratic Experience. New York: Dandom House, 1973.

BOSSARD, J. H. S.; BOLL, E. S. Ritual in Family Living. Philadelphia: University of Pennsylvania Press, 1950.

BROWNE, R. B. Ritual One. In: BROWNE, R. B. (Ed.). Rituals and Ceremonies in Popular Culture. Bowling Green, OH: Bowling Green University Popular Press, 1980. p. 1-18.

CAMPBELL, J. Myths to Live By. New York: Viking, 1972.

CAPLOW, T. Rule enforcement without visible means: Christmas gift giving in Middletown. American Journal of Sociology, v. 89, n. 6, p. 13061323, 1984.

CURRAY, P. M.; JIOBU, R. M. Big Mac and caneton à l'orange. In: BROWNE, R. B. (Ed.). Rituals and Ceremonies in Popular Culture. Bowling Green, OH: Bowling Green University Popular Press, 1980. p. 1-18.

DAUN, A. The materialistic lifestyle: some socio-psychological aspects. In UUSITALO, L. (Ed.). Consumer Behavior and Environmental Quality. New York: St. Martin's, 1983. p. 6-16.

DOUGLAS, M. Natural Symbols: Explorations in Cosmology. New York: Pantheon, 1974.

DOUGLAS, M.; ISHERWOOD, B. The World of Goods: Toward an Anthropology of Consumption. New York: Basic Books, 1979.

DURKHEIM, E. The Elementary Forms of the Religious Life. London: Allen and Unwin, 1912.

ELIADE, M. Rites and Symbols of Initiation. New York: Harper \& Row, 1965.

ELIADE, M. Myths, Rites, Symbols: A Mircea Eliade Reader. New York: Harper \& Row, 1975.

ERIKSON, E. H. Childhood and Society. New York: W. W. Norton, 1951. 
ERIKSON, E. H. Toys and Reasons: Stages in the Ritualization of Experience. New York: W. W. Norton, 1977.

ERIKSON, E. H. The Life Cycle Completed. New York: W. W. Norton, 1982.

EWEN, P. The Beauty Ritual. In: WAGNER, J. (Ed.). Images of Information. Beverly Hills, CA: Sage, 1979.

FARB, P.; ARMELAGOS, G. Consuming Passions: The Anthropology of Eating. Boston: Houghton Mifflin, 1980.

FELDMAN, D. C. The role of initiation activities in socialization. Human Relations, v. 30, n. 11, p. 977-990, 1977.

FIRTH, R. Symbols Public and Private. London: Allen and Unwin, 1973.

FREUD, S. The neuro-psychoses of defense. In: The Standard Edition of the Complete Works of Sigmund Freud. London: Hogarth Press and the Institute of Psycho-Analysis, 1962.

FREUD, S. Inhibitions, Symptoms and Anxiety. New York: W. W. Norton, 1959.

GARDNER, B. B.; LEVY, S. J. The product and the brand. Harvard Business Review, p. 33-39, 1955.

GEERTZ, C. Religion: anthropological study. In: SILLS, D. (Ed.). International Encyclopedia of the Social Sciences, v. 13. New York: The Macmillan Company and the Free Press, 1968. p. 285-290.

GENNEP, A. V. The Rites of Passage. London: Routledge \& Kegan Paul, 1908

GOFFMAN, E. The Presentation of Self in Everyday Life. Garden City, NY: Doubleday, 1959.

HARRISON, J. E. Themis: A Study of the Social Origins of Greek Religion. Cambridge, UK: Cambridge University Press, 1912.

HENRY, W. E. The Analysis of Fantasy. New York: John Wiley, 1956.

HOLBROOK, M. B.; HIRSCHMAN, E. C. The experiential aspects of consumer behavior: consumer fantasies, feelings, and fun. Journal of Consumer Research, v. 9, n. 2, p. 132-140, 1982.

HOLMAN, R. Product use as communication: a fresh appraisal of the venerable topic. In: ENIS, B. M.; ROERING, K. J. Review of Marketing. Chicago: American Marketing Association, 1981. p. 250-272.

HOPE, C. A. American beauty rituals. In: BROWNE, R. B. (Ed.). Rituals and Ceremonies in Popular Culture. Bowling Green, $\mathrm{OH}$ : Bowling Green University Popular Press, 1980. p. 1-18.

HUXLEY, J. A discussion on ritualization of behavior in animals and men. In: Philosophical Transactions of the Royal Society of London, Ser. B., n. 772 , v. 251. London: The Royal Society of London, 1966. p. 247-271.
JUNG, C. G. Psyche and Symbol. ed. Violet S. de Laszlo. Garden City, NJ: Doubleday, 1958.

JUNG, C. G. Researches in the Phenomenology of the Self. New York: Pantheon Books, 1959.

KEHRET-WARD, T.; JOHNSON, M. W.; LOUIE, T. A. Effects of ritual syntax on product categorization and evaluation. In: HOLBORRK, M. B.; HIRSCHMAN, E. C. (Eds.). Advances in Consumer Research. v. 12. Ann Arbor, MI: Association for Consumer Research, 1985. p. 319-324.

KOTTAK, C. P. Rituals at McDonald's. Natural History, v. 87, p. 75-82, 1978.

LEACH, E. R. Two essays concerning the symbolic representation of time. In: LESSA, W.; VOGT, E. Z. (Eds.). Reader in Comparative Religion. New York: Harper \& Row, 1958.

LEACH, E. R. Ritual. In: SILS, D. L. (Ed.). International Encyclopedia of the Social Sciences. v. 13. New York: Free Press, 1968. p. 520-526.

LEACH, E. R. Culture and Communication: The Logic By Which Symbols are Connected. Cambridge, UK: Cambridge University Press, 1976. p. 52.

LEVI-STRAUSS, C. The Savage Mind. Chicago: University of Chicago Press, 1962.

LEVY, S. J. Symbols for sale. Harvard Business Review, v. 37, n. 4, p. $117-$ 124, 1959.

LEVY, S. J. Marketplace Behavior: Its Meaning and Management. Chicago: Amacom, 1978.

LEVY, S. J. Interpreting consumer mythology: a structural approach to consumer behavior. Journal of Marketing, v. 45, n. 3, p. 49-61, 1981.

LEVY, S. J. Dreams, animals, fairy tales, and cars. Psychology and Marketing, n. 2, v. 2, p. 67-81, 1986.

LEVY, S. J.; ZALTMAN, G. Marketing Society, and Conflict. Englewood Cliffs, NJ: Prentice Hall, 1975.

LEVY, S. J.; CZEPIEL, J. A.; ROOK, D. W. Social division and aesthetic specialization: the middle class and musical events. In: HIRSCHMAN, E. C.; HOLBROOK, M. B. (Eds.). Symbolic Consumer Behavior. Ann Arbor, MI: Association for Consumer Research, 1981. p. 38-44.

MEAD, G. H. On Social Psychology. Ed. Anselm Strauss. Chicago: University of Chicago Press, 1956.

MINER, H. Body ritual among the Nacirema. American Anthropologist, v. 58, n. 3, p. 503-507, 1956.

MOL, H. Identity and the Sacred, New York: Free Press, 1976.

MOORE, S. F; MYERHOFF, B. G. Secular ritual: forms and meaning. In: MOORE, S. F; MYERHOFF, B. G. (Eds.). Secular Ritual. Amsterdam: Van Gorcum, 1977. p. 3-24. 
MUNN, N. Symbolism in a ritual context: aspects of symbolic action. In: HONIGMAN, J. (Ed.). Handbook of Social and Cultural Anthropology. Chicago: Rand McNally, 1973. p. 579-612.

MURRAY, H. A. Explorations in Personality. New York: Science Editions, 1938.

MURSTEIN, B. I. Theory and Research in Projective Techniques. New York: John Wiley, 1963.

NEWMAN, J. Motivation Research in Marketing Management. Cambridge, MA: Harvard University Press, 1958.

RAPPAPORT, D. Principles underlying projective techniques. Character and Personality, v. 10, p. 213-219, mar. 1942.

ROOK, D. W.; LEVY, S. J. Psychosocial themes in consumer grooming rituals. In: BAGOZZI, R. P.; TYBOUT, A. M. (Eds.). Advances in Consumer Research. v. 10. Ann Arbor, MI: Association for Consumer Research, 1983. p. 329-333.

SECORD, P. F; JOUARD, S. M. The appraisal of body cathexis: body cathexis and the self. Journal of Consulting Psychology, v. 17, n. 5, p. 343347,1953

SHERRY JR., J. F. Gift giving in anthropological perspective. Journal of Consumer Research. v. 10, n. 2, p. 157-168, 1983.

SHERRY JR., J. F. Some implications of consumer oral tradition for reactive marketing. In: KINNEAR, T. (Ed.). Advances in Consumer Research. v. 11. Ann Arbor, MI: Association for Consumer Research, 1984. p. 741-747.

SMITH, W. R. The Religion of the Semites. New York: Meridian, 1989.
SOLOMON, M. R. The role of products as social stimuli: a symbolic interactionism perspective. Journal of Consumer Research, v. 10, n. 3, p. 319-329, 1983.

SOLOMON, M. R.; ANAND, P. Ritual costumes and status transitions: the female suit as totemic emblem. In: HOLBROOK, M. B.; HIRSCHMAN, E. C. (Eds.). Advances in Consumer Research. V. 12. Ann Arbor, MI: Association for Consumer Research, 1985. p. 315-318.

STONE, G. P. Halloween and the mass child. American Quarterly, v. 13, n. 3, p. 372-379, 1959.

TURNER, V. The Ritual Process. Chicago: Aldine, 1969.

TYLOR, E. Primitive Culture: Researches into the Development of Mythology, Philosophy, Religion, Art and Custom. Gloucester, MA: Peter Smith, 1871.

VLAHOS, O. Body: The Ultimate Symbol. Philadelphia: J. B. Lippincott, 1979.

WARNER, W. L. The Living and the Dead: A Study f the Symbolic Life of Americans. New Haven, CT: Yale University Press, 1959.

WARNER, W. L.; MEEKER, M.; EELS, K. Social Class in America: A Manual of Procedure for the Measurement of Social Status. Chicago: Science Research Associates, 1949.

WAX. M. Themes in cosmetics and grooming. American Journal of Sociology, v. 62 , n. 6, p. 588-593, 1959.

WRIGHT, D. E.; SNOW, R. B. Consumption as ritual in the high technology society. In: BROWNE, R. B. (Ed.). Rituals and Ceremonies in Popular Culture. Bowling Green, OH: Bowling Green University Popular Press, 1980.

ZALTMAN, G.; WALLENDORF, M. Sociology: the missing chunk, or how we've missed the boat. Proceedings of the American Marketing Association Summer Educators' Conference. Chicago: American Marketing Association, 1977. p. 235-238.

\title{
Artigo convidado. Aprovado em 01.02.2006.
}

\author{
Dennis W. Rook \\ Professor de Marketing Clínico na Marshall School of Business - University of Southern \\ California. \\ Interesses de pesquisa nas áreas de comportamento e psicologia do consumidor, pesquisa \\ qualitativa, estratégia e planejamento de marketing. \\ E-mail: drook@marshall.usc.edu \\ Endereço: The Marshall School of Business at USC, Department of Marketing, Accounting \\ Building 301K, Los Angeles, CA - USA, 90089-0443.
}

